\title{
A abordagem da educação ambiental utilizando material audiovisual em periódicos CAPES
}

\author{
The approach of environmental education using audiovisual material in CAPES \\ journals
}

\section{El enfoque de la educación ambiental utilizando material audiovisual en revistas CAPES}

\author{
Daniela Brusamarelo ${ }^{1}$ \\ Sandra Regina Longhin ${ }^{2}$ \\ Emanuele Brusamarelo ${ }^{3}$
}

\begin{abstract}
Resumo
Este artigo integra os estudos empreendidos em nossa pesquisa de mestrado que investigou a abordagem da Educação Ambiental em material audiovisual utilizado na prática docente da educação básica. Desse modo, o objetivo desse trabalho foi investigar e analisar o que tem sido pesquisado e publicado em periódicos CAPES considerando esse contexto. Para tanto, foram selecionados artigos publicados nesse portal nos últimos 10 (dez) anos e analisados aqueles publicados em revistas com conceito CAPES Qualis A, totalizando 8 (oito) artigos. Nessas publicações, predomina a pesquisa sobre a utilização das Tecnologias de Informação e Comunicação em cursos de formação continuada e de pós-graduação em Educação Ambiental. A abordagem da Educação Ambiental em material audiovisual (filmes) na prática docente da educação básica foi identificada somente em uma publicação. Em relação à diversidade de concepções e práticas de Educação Ambiental identificamos que parte dos artigos introduz e contrapõe a abordagem conservadora e a crítica. O debate sobre a efetivação da abordagem interdisciplinar da Educação Ambiental é, ainda, incipiente nas publicações.
\end{abstract}

Palavras-chave: Educação ambiental. Material audiovisual. Tecnologia de Informação e Comunicação.

\begin{abstract}
This article integrates the studies undertaken in our master's research that investigated the approach of Environmental Education in audiovisual material used in the teaching practice of basic education. Thus, the objective of this work was to investigate and analyze what has been researched and published in CAPES journals considering this context. For that purpose, articles published in this portal were selected in the last 10 (ten) years and analyzed those published in journals with CAPES Qualis A concept, totaling 8 (eight) articles. In these publications, research on the use of Information and Communication Technologies in continuing education and postgraduate courses in Environmental Education predominates. The approach of Environmental Education in audiovisual material (films) in the teaching practice of basic education was identified only in one publication. About the diversity of conceptions and practices of Environmental Education, we identify that part of the articles introduces and contrasts the conservative and critical approach. The debate about the effectiveness of the interdisciplinary approach of Environmental Education is still incipient in the publications.
\end{abstract}

Keywords: Environmental education. Audiovisual material. Information and Communication Technology.

\footnotetext{
${ }^{1}$ Mestra em Educação para Ciências e Matemática. Professora da rede estadual de ensino do Estado de Mato Grosso. Secretaria de Estado de Educação (SEDUC/MT). Rondonópolis, Mato Grosso, Brasil. E-mail: dankerberos@hotmail.com.

${ }^{2}$ Doutora em Química. Professora do Instituto Federal de Educação, Ciência e Tecnologia de Goiás - Câmpus Goiânia (IFG/GO). Goiânia, Goiás, Brasil. E-mail: srlonghin@ gmail.com.

${ }^{3}$ Doutora em Ciência Animal. Universidade Federal de Mato Grosso (UFMT) - Câmpus Cuiabá. Cuiabá, Mato Grosso, Brasil. E-mail: brusamareloe@ hotmail.com.
} 


\section{Resumen}

Este artículo integra los estudios emprendidos en nuestra investigación de maestría que investigó el abordaje de la Educación Ambiental en material audiovisual utilizado en la práctica docente de la educación básica. De este modo, el objetivo de este trabajo fue investigar y analizar lo que ha sido investigado y publicado en revistas CAPES considerando ese contexto. Para ello, se seleccionaron artículos publicados en ese portal en los últimos 10 (diez) años y analizados aquellos publicados en revistas con concepto CAPES Qualis A, totalizando 8 (ocho) artículos. En estas publicaciones, predomina la investigación sobre la utilización de las Tecnologías de la Información y la Comunicación en la formación continua y los cursos de posgrado en Educación Ambiental. El enfoque de la Educación Ambiental en material audiovisual (películas) en la práctica docente de la educación básica fue identificada solamente en una publicación. En relación a la diversidad de concepciones y prácticas de Educación Ambiental identificamos que parte de los artículos introduce y contrapone el enfoque conservador y la crítica. El debate sobre la efectividad del enfoque interdisciplinario de la Educación Ambiental es, aún, incipiente en las publicaciones.

Palabras clave: Educación ambiental. Material audiovisual. Tecnología de la Información y la Comunicación.

\section{Introdução}

Este trabalho investiga a abordagem da educação ambiental em material audiovisual utilizado na prática docente da educação básica a partir de publicações na forma de artigos científicos. A escolha por investigar publicações no portal de periódicos da Coordenação de Aperfeiçoamento de Pessoal de Nível Superior (CAPES) foi considerada, pois se configura em fonte expressiva de produção científica, acessível à comunidade acadêmica e à sociedade. Nesse sentido, a análise realizada sobre o que tem sido publicado em periódicos disponíveis na plataforma CAPES tem o objetivo de contribuir para a compreensão dos estudos e pesquisas acerca da abordagem da Educação Ambiental (EA) utilizando material audiovisual na prática docente, os níveis de ensino em que ocorrem (com ênfase na educação básica), as áreas do saber ou disciplinas contemplados, os resultados que têm sido obtidos e se discutem a interdisciplinaridade da EA.

Partimos do entendimento de autores como Sauvè (2005), Sorrentino (2006) e González-Gaudiano (2007) de que a construção da EA, no ensino formal e não formal, tem sido conduzida por meio de concepções e práticas diversas, tanto pelos atores que as praticam quanto pelos materiais que as veiculam, direcionando a resultados também distintos. Constatando essa pluralidade de saberes e práticas, esses autores propõem categorizá-la, na forma de correntes, com o intuito de cercar e organizar esse universo.

Convém destacar que, dentre tais estudiosos, Sauvè (2005), ao analisar bases de dados norte-americanas e europeias - que concentram publicações da área educacional, incluindo a EA -, organizou uma cartografia ${ }^{4}$ contendo quinze correntes, contemplando as mais antigas até as mais recentes. Acerca delas, destacamos a conservacionista/recursista, que de acordo com Loureiro (2012) e Leff (2013) predomina no ensino formal e apresenta uma concepção de ambiente limitada aos recursos naturais, a gestão ambiental com ênfase no descarte, reaproveitamento e reciclagem de resíduos. Já a corrente crítica social, que contrapõe a abordagem conservacionista/recursista, apresenta uma leitura de ambiente em que a dimensão social, a econômica e a natural estão interrelacionadas e que a transformação da relação sociedade-natureza passa pela transcendência da racionalidade econômica em uma nova

\footnotetext{
${ }^{4}$ O termo é utilizado pela autora no sentido de ser um esforço de sistematizar e apresentar as proposições pedagógicas no campo da educação ambiental.
} 
racionalidade ambiental (LEFF, 2013). Essa corrente é entendida por Loureiro (2012) e Leff (2013) como um dos caminhos, embora não o único, para a abordagem da EA na educação formal básica com vistas à sustentabilidade.

Quanto aos materiais instrucionais, de apoio ao professor para a prática da EA, estão organizados e disponíveis em meio impresso e digital. No meio digital, a internet contribui com a disseminação acentuada de materiais que abordam esse tipo de educação no início do século XXI (MORÁN, 2001). Esse meio ampliou a acessibilidade dos professores a materiais instrucionais que podem ser utilizados nos processos de ensino, como websites, jogos didáticos, simulações, vídeos de curta duração, documentários e filmes.

No âmbito das Tecnologias de Informação e Comunicação (TIC), estão postas na sociedade e são por ela construídas e assimiladas. Os documentos reguladores da educação nacional - como a Lei de Diretrizes e Bases da Educação Nacional LDB n 9.394/1996 e as Diretrizes Curriculares da Educação Básica (CNEB) - preveem a sua incorporação aos processos de ensino da Educação Básica. Em específico sobre os materiais audiovisuais, na modalidade cinema, a sua utilização está contemplada na LDB em caráter obrigatório. Em seu art. 26, inciso 8, a lei preconiza que a exibição de filmes de produção nacional deve constituir componente curricular complementar integrado à proposta pedagógica da escola, sendo a sua exibição obrigatória por, no mínimo, duas (02) horas mensais (BRASIL, 1996).

Considerando esse contexto, da diversidade de concepções e práticas da EA na educação formal bem como a disponibilidade de materiais instrucionais, a análise do que tem sido publicado e disponibilizado no portal de periódicos CAPES podem contribuir para a reflexão sobre o enfoque predominante nas pesquisas e a abordagem de EA privilegiada.

\section{Levantamento de publicações em EA no portal de periódicos CAPES}

A análise do que tem sido produzido na forma de artigos, na área da EA, focalizou especificamente a utilização de materiais impressos e digitais (com foco nos materiais audiovisuais) para a prática da EA na educação formal e a abordagem das correntes em EA nessas publicações. O processo de busca considerou a presença do termo Tecnologias de Informação e Comunicação (TIC), em função de sua generalidade ao referir-se à diversidade de recursos tecnológicos, dentre os quais os materiais audiovisuais utilizados na educação.

A busca dos artigos que constituíram nosso corpus de análise foi realizada no mês de dezembro de 2016, a partir da inserção do termo educação ambiental na opção Buscar assunto, obtendo um retorno de 1.478 resultados.

A pesquisa foi então delimitada por meio da opção Busca avançada, selecionando as publicações dos últimos dez anos. Esse recorte temporal foi considerado por observarmos que nos anos de 1990 e início dos anos 2000 autores ampliavam os estudos sobre as concepções e as práticas da EA buscando categorizá-las (SORRENTINO, 1995; SAUVÈ, 2005; SORRENTINO, 2006). O período foi considerado, ainda, por emergirem estudos relacionados às trajetórias da EA e sua abordagem no meio digital (MORÁN, 2001; GONZÁLEZGAUDIANO, 2007). Na sequência, em Tipo de material especificou-se a modalidade Artigos, com retorno de 1.250 resultados.

Assim, ao término da leitura inicial da apresentação de cada um dos artigos, no momento da busca avançada, foram selecionados os que apresentavam referência direta à utilização de tecnologias e/ou a análise de materiais impressos e digitais na prática da EA no ensino formal. Especificamente observamos se em sua apresentação evidenciavam-se os termos concepções de Educação Ambiental, material impresso, TIC, vídeo. 
Como resultado desse processo de busca, obtivemos vinte e quatro (24) artigos que contemplaram os critérios estabelecidos. Desse total, foram selecionados os periódicos que abordavam a EA na prática e/ou formação docente, publicados em revistas com conceito CAPES Qualis A. Consideramos esse escopo devido ao fator de impacto dessas publicações e a qualidade da produção intelectual dos materiais, totalizando oito (08) periódicos que constituíram o corpus da análise, doravante denominados $\mathrm{A} 1^{5}$ a A8 e apresentados no Quadro 1.

Quadro 1 - Artigos sobre a abordagem da EA em material audiovisual e impresso

\begin{tabular}{|c|c|c|c|c|}
\hline Código & Título & Autor(es) & Ano & Endereço eletrônico \\
\hline A1 & $\begin{array}{l}\text { Reflexões sobre o } \\
\text { uso das TIC por } \\
\text { professores e } \\
\text { programas de Pós- } \\
\text { graduação em } \\
\text { educação ambiental } \\
\text { do Brasil e da } \\
\text { Espanha }\end{array}$ & $\begin{array}{l}\text { Joaquín } \\
\text { Paredes, } \\
\text { Rogério Dias } \\
\text { de Arruda. }\end{array}$ & 2007 & $\begin{array}{l}\text { http://relatec.unex.es/art } \\
\text { icle/download/309/289 }\end{array}$ \\
\hline A2 & $\begin{array}{l}\text { Educação ambiental } \\
\text { e as novas } \\
\text { tecnologias de } \\
\text { informação e } \\
\text { comunicação }\end{array}$ & $\begin{array}{l}\text { Gelze Serrat } \\
\text { de Souza } \\
\text { Campos } \\
\text { Rodrigues, } \\
\text { Marlene T. } \\
\text { de Muno } \\
\text { Colesanti. }\end{array}$ & 2008 & $\begin{array}{l}\text { http://www.seer.ufu.br/i } \\
\text { ndex.php/sociedadenatu } \\
\text { reza/article/download/9 } \\
398 / 5743\end{array}$ \\
\hline A3 & $\begin{array}{l}\text { As tecnologias } \\
\text { educacionais na } \\
\text { formação em } \\
\text { Educação } \\
\text { Ambiental para a } \\
\text { sustentabilidade }\end{array}$ & $\begin{array}{l}\text { Antonio } \\
\text { Fernando } \\
\text { Silveira } \\
\text { Guerra. }\end{array}$ & 2010 & $\begin{array}{l}\text { http://www2.pucpr.br/re } \\
\text { ol/index.php/dialogo?d } \\
\text { d99=pdf\&dd1=4292 }\end{array}$ \\
\hline A4 & $\begin{array}{l}\text { Fotografia de } \\
\text { natureza como } \\
\text { instrumento para } \\
\text { educação ambiental }\end{array}$ & $\begin{array}{l}\text { Marilia } \\
\text { Dammski } \\
\text { Borges, José } \\
\text { Marcelo } \\
\text { Aranha, José } \\
\text { Sabino. }\end{array}$ & 2010 & $\begin{array}{l}\text { http://www.scielo.br/pd } \\
\text { f/ciedu/v16n1/v16n1a0 } \\
\text { 9.pdf }\end{array}$ \\
\hline A5 & $\begin{array}{l}\text { Educação } \\
\text { ambiental, } \\
\text { sustentabilidade e } \\
\text { ciência: o papel da } \\
\text { mídia na difusão de } \\
\text { conhecimentos } \\
\text { científicos }\end{array}$ & $\begin{array}{l}\text { Samia } \\
\text { Nascimento } \\
\text { Sulaiman. }\end{array}$ & 2011 & $\begin{array}{l}\text { http://www.scielo.br/pd } \\
\text { f/ciedu/v17n3/a08v17n } \\
\text { 3.pdf }\end{array}$ \\
\hline
\end{tabular}

\footnotetext{
${ }^{5}$ A1, An: Artigo 1, Artigo n.
} 


\begin{tabular}{|l|l|l|c|l|}
\hline Código & \multicolumn{1}{|c|}{ Título } & Autor(es) & Ano & \multicolumn{1}{c|}{ Endereço eletrônico } \\
\hline A6 & $\begin{array}{l}\text { O cinema como } \\
\text { componente } \\
\text { didático da } \\
\text { educação ambiental }\end{array}$ & $\begin{array}{l}\text { Fernando Zan } \\
\text { Vieira, } \\
\text { Ademir José } \\
\text { Rosso. }\end{array}$ & 2011 & $\begin{array}{l}\text { http://www2.pucpr.br/re } \\
\text { ol/index.php/dialogo?d } \\
\text { d99=pdf\&dd1=5067 }\end{array}$ \\
\hline A7 & $\begin{array}{l}\text { La motivación del } \\
\text { uso de las tic em la } \\
\text { formación de } \\
\text { professorado em } \\
\text { educación } \\
\text { ambiental }\end{array}$ & $\begin{array}{l}\text { Joaquín } \\
\text { Paredes, } \\
\text { Rogério Dias } \\
\text { de Arruda. }\end{array}$ & 2012 & $\begin{array}{l}\text { http://www.scielo.br/pd } \\
\text { f/ciedu/v18n2/a08v18n } \\
\text { 2.pdf }\end{array}$ \\
\hline A8 & $\begin{array}{l}\text { Avaliação de um } \\
\text { minicurso sobre o } \\
\text { uso de jogos no } \\
\text { ensino }\end{array}$ & $\begin{array}{l}\text { Lya Christina } \\
\text { da Costa } \\
\text { Brito et al. }\end{array}$ & 2012 & $\begin{array}{l}\text { http://ojs.rbpg.capes.go } \\
\text { v.br/index.php/rbpg/arti } \\
\text { cle/view/257/246 }\end{array}$ \\
\hline
\end{tabular}

Fonte: elaborado pelas autoras, 2017.

\section{Análise dos materiais}

A partir da leitura flutuante desses materiais, procedemos à análise preliminar, identificando que as publicações se concentraram nos anos de 2007 a 2012 e abordavam a EA e as tecnologias impressas e digitais. Dessa forma, organizamos os materiais em duas categorias: a EA e o material impresso e audiovisual (A4, A5, A6, A8); a EA e as TIC (A1, A2, A3, A4, A7). Na parte final, iniciamos algumas reflexões a partir do estudo realizado.

A metodologia de análise seguiu a proposta de Minayo (1998) que define categorias temáticas de análise. Assim, organizamos as seguintes categorias de análise: 1 - tipo de material instrucional para EA investigado, 2 - objetivo proposto, 3 - enfoque da EA e/ou das TIC, 4 - resultados. A partir dessa análise organizamos os materiais em dois grupos: os que abordam os materiais instrucionais impressos e audiovisuais para a prática docente na EA, os que dialogam sobre a relação da EA e as TIC no ensino.

\subsection{A educação ambiental no material impresso e audiovisual}

Nessa categoria foram incluídos os materiais A4, A5, A6 e A8. O primeiro estudo, A4, de Borges, Aranha e Sabino (2010), discute a utilização e a contribuição da fotografia para a instrumentalização no aprendizado da EA. O estudo de caso foi baseado na aplicação da palestra intitulada "A importância da natureza e o impacto causado pelo homem", ministrada para alunos do ensino fundamental, na modalidade de Ensino de Jovens e Adultos (EJA), da rede pública de ensino dos estados do Paraná e de Santa Catarina.

A ênfase no estudo centrou-se na abordagem dos conceitos e das características inerentes à fotografia (digital), destacando seu potencial perceptivo. A avaliação da melhora do aprendizado, por parte dos autores, ocorreu a partir da aplicação de questionários aos alunos, confrontando os resultados entre os dois grupos, nos quais somente em um foi abordada a EA utilizando slides com fotografia. Os autores concluíram que a fotografia é eficiente como sensibilizadora, sendo versátil em sua utilização nos diferentes níveis de ensino. 
Na sequência, o artigo A5, de Sulaiman (2011), analisa o material impresso de apoio ao professor da educação básica, da série "Sustentabilidade na Escola", publicado na revista "Carta na Escola" no período de 2007 a 2008. A finalidade foi investigar o discurso da sustentabilidade nesses materiais, que são utilizados na prática docente em EA. A autora defende uma abordagem crítica da EA e aponta que a mídia tem papel importante na difusão de informações, agregando notoriedade à temática ambiental, ressaltando, porém, a necessidade de se analisar os conteúdos e as estratégias utilizadas.

Embora Sulaiman (2011) não tenha analisado o material com base em correntes de EA já estabelecidas, deixa evidente, em sua narrativa, que o discurso da sustentabilidade está presente no material, vem em uma perspectiva conservadora e que uma abordagem crítica é necessária:

\begin{abstract}
A análise dialógica do discurso da sustentabilidade veiculada na série "Sustentabilidade na Escola", a que procedemos neste artigo, evidencia, portanto, a limitação de se difundirem conhecimentos científicos e avanços tecnológicos para defender um processo de sustentabilidade sem uma abordagem crítica sobre a quem se dirige esse discurso e quem se beneficia com ele [...] o articulista coloca a responsabilidade dessa nova forma de produzir e consumir sobre o "livre-arbítrio" do consumidor, sem considerar as desigualdades sociais, culturais e econômicas que limitam a escolha individual. (SULAIMAN, 2011).
\end{abstract}

$\mathrm{Na}$ análise, a autora concluiu que o material é limitante como estratégia de EA. O trabalho apresenta um discurso de sustentabilidade que exalta o poder da ciência sobre a sociedade, desconsiderando essencialmente as implicações sociais, legitimando o capitalismo e a expansão industrial. Visando à utilização do material para a prática da educação ambiental, sugere-se tomá-lo como exemplo de uma visão fragmentada da questão ambiental e de suas consequências na formação de opinião pública, visto que ele é um veículo de comunicação de massa.

Quanto ao artigo A6, de Vieira e Rosso (2011), este tem por objetivo analisar a utilização do cinema na EA, considerando a recepção, o aprendizado da temática ambiental a partir da exibição do filme e o papel mediador do professor frente às TIC. O público-alvo foram alunos do ensino fundamental ( $5^{\mathrm{a}}$ e $6^{\mathrm{a}}$ séries) da rede pública paranaense.

Para tanto, os autores contrapõem a EA em uma abordagem conservadora, almejando uma abordagem crítica, por meio da incorporação da mídia na modalidade cinema nessa perspectiva. Quanto aos filmes, os autores conceituam, caracterizam e fundamentam a utilização desse material no ensino, destacando a modalidade de cinema de impacto ambiental, sugerindo películas voltadas para a corrente crítica.

Apesar de não explicitarem qual o percurso metodológico da incorporação da mídia nesse estudo de caso, eles concluíram que o cinema na educação é um ponto de partida útil para o aprendizado, uma vez que possibilita ir além dos conteúdos, promovendo uma mudança de atitudes e valores. Apontam, ainda, que o professor tem importante papel nesse processo de mediação e que é de grande relevância a escolha de produções cinematográficas voltadas aos problemas ambientais em uma abordagem crítica, tratando dos prejuízos causados diretamente pela ação humana (VIEIRA; ROSSO, 2011).

No trabalho A8 de Brito et al. (2012), também foram utilizados materiais impressos (jogos de mesa) sobre conteúdos de Química e EA. O objetivo dos autores foi o de instrumentalizar a prática de licenciandos de diversos cursos de Catalão-GO, por meio da aplicação de minicurso utilizando jogos. Após essa intervenção, os participantes da pesquisa avaliariam a estratégia de ensino entendendo que o jogo contribui positivamente e facilita a 
aprendizagem, sendo um recurso atraente para o ensino. Dentre os jogos utilizados, destacouse a Trilha da Reciclagem, voltado para a prática dos $3 \mathrm{R}$, considerado o de mais fácil compreensão pelo grupo.

Analisando esses artigos, observa-se que somente o A5 realizou uma análise do conteúdo, discutindo as concepções de sustentabilidade, em material impresso. Considerando a utilização de materiais audiovisuais (filmes) para a prática da EA, o artigo A6 direcionou a discussão para a categoria de cinema de impacto ambiental, sugerindo materiais para a prática da EA que entende estarem na perspectiva crítica. No entanto, não evidencia se realizou a análise das concepções de educação ambiental nos materiais sugeridos para a abordagem crítica e quais filmes foram utilizados na investigação junto aos alunos.

Os artigos A4 e A8 enfatizaram as características de recursos como a fotografia, os jogos de mesa e a aplicação, não explicitando discussão sobre a EA, tampouco as concepções presentes nos materiais utilizados. Os estudos preocuparam-se em avaliar os efeitos de tal uso, mas sem deixar claro qual abordagem pretendiam atingir.

Em relação à discussão teórica sobre as concepções de EA, os artigos A5 e A6 apresentam uma seção específica para o tratamento do tema. Ambos evidenciam a contraposição entre a abordagem da EA conservadora e a crítica e explicitam a defesa pela abordagem em uma perspectiva crítica.

Quanto ao público-alvo dos estudos, dois trabalhos (A4 e A6) direcionaram o foco para o ensino fundamental e um estudo (A8) voltou-se para a formação inicial de licenciandos. Nessas publicações, não foi observada menção à prática transversal, à abordagem interdisciplinar da EA ou à(s) disciplina (s) envolvida (s).

\subsection{A educação ambiental e as tecnologias de informação e comunicação}

Integram esta categoria os materiais A1, A2, A3 e A7. O artigo A1, de Arruda (2007), pesquisou o aspecto da motivação para a utilização das TIC (computadores, projetor multimídia, softwares, dentre outros), por professores e alunos da pós-graduação, na formação de educadores ambientais de um curso de doutorado, em um estudo de caso de uma realidade da Espanha e do Brasil. A finalidade foi verificar, por meio da aplicação de questionário, o papel exercido pela motivação no uso das TIC nesse público.

O estudo apontou que, para os alunos, não há consenso sobre o caráter motivador das TIC e, para os professores, são diversos os discursos acerca da sua importância. A prática docente que usa esses recursos é constante e influenciada por fatores como a crença do valor atribuído às TIC. Os professores também ressaltam que as condições de utilização das TIC não são boas nas universidades. Quanto às tecnologias mais utilizadas, evidenciou-se o computador, a internet, o e-mail, o Power Point, o Compact Disk (CD-ROM), o projetor multimídia e os mapas conceituais via software (ARRUDA, 2007).

Na sequência, o artigo A2, de Rodrigues e Colesanti (2008), abordou a potencialidade do uso dos princípios da EA por meio da hipermídia (integração de recursos como texto, som e elementos gráficos). As autoras debatem as concepções de EA no âmbito da sustentabilidade, na perspectiva conservadora e na emancipadora/crítica, adotando essa última abordagem vinculada à pedagogia da complexidade e à interação entre as TIC e a sociedade nos diferentes períodos históricos.

Nesse trabalho, Rodrigues e Colesanti (2008) apontam elementos fundamentais para a produção de material didático em EA no meio audiovisual no âmbito de uma concepção multidimensional. A abordagem nessa perspectiva envolve o enfoque interdisciplinar, como 
as características de comunicação, de informação, de interatividade e de navegação proporcionadas pelas TIC.

As autoras concluíram que a incorporação das TIC no ensino demanda mudanças de atitudes, de valores, novos métodos educacionais e comportamentais. A EA necessita de materiais ajustados ao seu tempo tecnológico, possibilitando a emancipação de tecnologias integradas ao processo de reflexão sobre o conteúdo apresentado aos usuários. A hipermídia é apontada pelas autoras como uma estratégia educacional que pode inovar a prática didática cotidiana.

O artigo A3, de Guerra (2010), trata da temática da sustentabilidade como tema para a formação continuada de professores da rede municipal e estadual no estado de Santa Catarina, por meio da utilização de Ambiente Virtual de Aprendizagem (AVA). Os recursos utilizados foram mapas conceituais, $b \log s$, jogos e ferramentas dispostas nesse ambiente.

Partindo da discussão da tríade EA, TIC e formação docente, o trabalho propõe a utilização das TIC para a mudança nas práticas em EA, em uma abordagem crítica, afastandose da tradicional, tecnicista, pois destaca que essa última predomina no ensino. Após o trabalho desenvolvido, o autor deduziu que houve uma mudança de abordagem da educação ambiental nos projetos elaborados por alguns participantes, distanciando-se da concepção conservadora e aproximando-se da concepção crítica. Em relação às TIC, ele concluiu que há demanda pela implementação, nas escolas, de melhorias na infraestrutura e nos recursos humanos. Evidenciou, ainda, a necessidade de aperfeiçoamento técnico, metodológico e epistemológico em relação ao uso das TIC para a prática em EA (GUERRA, 2010).

Na sequência, o trabalho A7, de Paredes e Arruda (2012), investigou a utilização das TIC por professores em um curso de doutorado na área de formação ambiental, no Brasil e na Espanha. Os autores apresentam e defendem uma abordagem crítica da EA, debatem os níveis de importância das TIC e seu uso na perspectiva crítica, posicionando-se em um meio termo, no qual as TIC não são nem redentoras nem ameaçadoras.

Após analisarmos os artigos que envolvem as TIC e a EA, entendemos que, em maior número, os trabalhos estão voltados para a abordagem da importância, da utilização, da motivação e das contribuições das TIC. Eles voltam-se para a investigação de alunos e professores de cursos de pós-graduação em EA (A1, A7) e formação continuada de professores da educação básica (A3).

Quanto à abordagem da EA, os artigos A1, A2, A3, A5 e A6 apresentaram uma seção em que os autores discutem as concepções de Educação Ambiental conservadora e crítica e defendem essa última concepção. De modo que nos cinco artigos, unanimemente, a abordagem de educação ambiental crítica é defendida.

\subsection{Algumas reflexões sobre os resultados obtidos}

Considerando o escopo de estudo selecionado identificamos que as práticas da EA são discutidas com maior intensidade, em termos de fundamentação teórica, nos trabalhos desenvolvidos por pós-graduandos ou com formação acadêmica nesse nível já concluída.

Acerca do fluxo de publicações de materiais referentes aos meios de comunicação e à temática ambiental, convém destacar o estudo de Román Nunez e Cuesta Moreno (2016). Ao investigar publicações na área em bases de dados da América Latina, Caribe, Espanha e Portugal, os autores concluíram que elas são relativamente recentes e predomina o tema da conservação ambiental. Eles concluem que os meios de comunicação desenvolvem um trabalho informativo, contudo, apresentam uma abordagem passiva dos temas ambientais, posto que não buscam explicações para as causas de tais problemas e tampouco assumem 
posições críticas e reflexivas que apontem soluções (ROMÁN NUNEZ; CUESTA MORENO, 2016).

Como visto, os autores reconhecem que está consolidada a relação entre a diversidade dos meios de comunicação e o ambiente. No entanto, seu potencial tem sido utilizado em caráter informativo ao não se aprofundarem em identificar as causas da problemática ambiental, em buscar soluções, assumindo uma postura crítica e reflexiva.

Em relação à área de acesso livre da plataforma, considerando a investigação do tema educação ambiental nas publicações de artigos dos últimos dez anos, evidenciou-se que a EA é abordada nas diferentes áreas, com predomínio de trabalhos que a associam à educação, à saúde e à administração, com enfoques diversos. No caso dos artigos selecionados, alguns também não apresentaram uma discussão teórica sobre a EA. Assim sendo, isso pode constituir-se em um entrave enquanto meio de atualização de estudo sobre o que tem sido discutido e pesquisado em relação à prática da EA em relação à educação básica de nível médio.

Quanto à abordagem das TIC, as discussões enfocam elementos diversos. Nos artigos A8 e A4 foi observada a preocupação em explicitar as características e potencialidades das tecnologias para o ensino. Outros materiais, como o A7, aprofundam a discussão sobre os níveis de importância das TIC e se posicionam frente à questão da neutralidade destas:

[...] penso que essa postura sobre a neutralidade da TIC (considerando-as meros apoios à transmissão de informação) já não cabe mais no momento atual, até porque seriam ignorados aspectos como, por exemplo, as intenções presentes nas próprias tecnologias, o que levaria ao entendimento de que não há o interesse de fazer um uso crítico e reflexivo das TIC, consequentemente relevando o descompromisso com o processo desencadeado por esse uso, que pode ser positivo, ao possibilitar ações transformadoras necessárias à sociedade, ou negativo, ao estimular a prática corrente fundada no capitalismo. (PAREDES; ARRUDA, 2012).

De modo geral, há, nas publicações, o entendimento de que, no âmbito das TIC, elas estão postas na sociedade e podem contribuir quando incorporadas à educação ambiental. No entanto, alguns estudos (A1, A2, A3, A7) ponderam que essa relação não é de simples tratamento ao considerarem que a incorporação das TIC no ensino envolve questões como a formação epistemológica de professores, a análise das estratégias de utilização, os conteúdos propostos e a atuação do professor como mediador desse processo.

Todavia, não encontramos, nessas publicações, investigações que tratassem de estudar as concepções e práticas de EA em materiais impressos ou digitais utilizados na educação básica, de forma a discuti-los com base nas correntes que têm sido propostas na literatura, como em Sauvè (2005), Sorrentino (2006) e González-Gaudiano (2007).

A maior proporção dos trabalhos (A1, A3, A7 e A8) voltaram-se para o estudo da utilização das TIC (computador, internet, projeto multimídia, softwares diversos) na formação inicial e continuada de professores da educação básica e com alunos e professores da pósgraduação em formação ambiental. As investigações se concentraram na realidade das regiões Sudeste e Sul do Brasil e Espanha. Assim, a pesquisa relacionada à utilização de materiais instrucionais para a prática da EA na educação básica, em específico para o ensino médio, não foi observada nesse corpus.

Nos dois casos que envolveram a participação de alunos da educação básica, no ensino fundamental (A4 e A6), não foi explicitada a articulação da prática em EA com uma área, disciplina ou conteúdos curriculares específicos. Dessa forma, não foi possível observar a efetivação da prática docente em EA por meio da transversalidade, ou se há predominância da efetivação da EA em determinadas disciplinas em detrimento de outras. 
Do mesmo modo, o caráter interdisciplinar da EA é pouco mencionado, sendo explicitamente discutido somente na seção teórica do artigo A2. Essa característica vem ao encontro do entendimento de González-Gaudiano (2007) de que a EA, desde os primórdios, encontrou na interdisciplinaridade um recurso conveniente para integrar os diversos campos e saberes, mas que não se abre a um debate apropriado para lhe dar a devida especificidade.

Para Leff (2002), embora o entendimento de que a demanda pela interdisciplinaridade para tratar da complexidade da problemática ambiental seja "dificilmente questionável em sua formulação geral", esta não tem sido traduzida em caminho teórico e prático que efetive a integração dos diversos campos do saber. De acordo com o autor, essa abordagem pouco contribui para o desenvolvimento de uma concepção integrada dos processos históricos, econômicos, políticos e sociais que originaram a problemática ambiental e a promoção da relação sustentável da sociedade-natureza.

\section{Considerações finais}

Postos esses entendimentos, consideramos que o campo da pesquisa sobre as diferentes concepções e práticas de EA envolvendo a utilização de material audiovisual, na prática docente na educação básica, é de modo geral, um terreno fértil para novos estudos. Há ainda necessidade de publicação de artigos científicos, em termos de ampliar o debate sobre a abordagem da Educação Ambiental diante da diversidade dos caminhos percorridos, da gama de materiais audiovisuais disponíveis e os resultados aos quais conduzem.

O debate sobre a interdisciplinaridade é, ainda, incipiente nos artigos analisados. Da mesma forma, nos trabalhos que envolveram a pesquisa sobre a prática efetiva da EA na educação básica, a abordagem interdisciplinar da EA não foi privilegiada. Essa realidade vem de encontro com o que estabelecem e regulamentam as diretrizes curriculares para a educação básica e para a educação superior no âmbito da EA.

Os periódicos CAPES, enquanto fonte de atualização sobre pesquisas na área educacional que disseminam estudos sobre a compreensão das abordagens da EA nos materiais audiovisuais - utilizados por professores da educação básica para a prática desta -, podem contribuir para clarear os rumos da EA no ensino e encaminhar novos direcionamentos. $\mathrm{O}$ desenvolvimento da pesquisa e da produção científica que subsidiem o debate sobre as categorizações da EA, a prática interdisciplinar utilizando material audiovisual, em uma abordagem crítica no ensino formal, poderá contribuir com essa perspectiva.

\section{Referências}

ARRUDA, R. D. de. Reflexões sobre o uso das TIC por professores de programas de pósgraduação em educação ambiental do Brasil e da Espanha. Revista Lationoamericana de Tecnología Educativa, v. 6, n. 1, p. 79-96, 2007. Acesso em: 11/12/2016.

BORGES, M. D.; ARANHA, J. M.; SABINO, J. A fotografia de natureza como instrumento para educação ambiental. Ciência \& Educação, v. 16, n. 1, p. 149-161, 2010. Acesso em: 09/12/2016.

BRASIL. Lei no 9.394, de 20 de dezembro de 1996. Estabelece as Diretrizes e Bases da Educação Nacional. Diário Oficial da União, Brasília, DF, v. 134, n. 248, 23 de dez. 1996. Seção 1, p. 27834-27841. 
BRITO, L. C. da C.; BORGES, A. P. A.; BORGES, C. de O.; SANTOS, D. G. dos.; MARCIANO, E. da P.; NUNES, S. M. T. Avaliação de um minicurso sobre o uso de jogos no ensino. Revista Brasileira de Pós-Graduação, v. 8, n. 2, p. 589-615, 2012. Acesso em: 09/12/2016.

GONZÁLEZ-GAUDIANO, E. Educación ambiental: trayectorias, rasgos y escenarios. México: Plaza y Valdés Editores, 2007.

GUERRA, A. F. S. As tecnologias educacionais na formação em Educação Ambiental para a sustentabilidade. Revista Diálogo Educacional, v. 10, n. 31, p. 561-579, 2010. Acesso em: 09/12/2016.

LEFF, E. Epistemologia ambiental. Tradução de: SANDRA VALENZUELA. 5. ed. São Paulo: Cortez, 2002.

LEFF, E. Saber ambiental: sustentabilidade, racionalidade, complexidade, poder. Tradução de: LÚCIA MATHILDE ENDLICH ORTH. 10. ed. Rio de Janeiro: Vozes, 2013.

LOUREIRO, C. F. B. Trajetórias e fundamentos da educação ambiental. 4. ed. São Paulo: Cortez, 2012.

MINAYO, M. C. de S. O desafio do conhecimento: pesquisa qualitativa em saúde. 5. ed. São Paulo: Hucitec-Abrasco, 1998.

MORÁN, J. M. Educação ambiental na internet e cd-rom. In. TRAJBER, R.; COSTA, L. B. (Org.). Avaliando a educação ambiental no Brasil: materiais audiovisuais. Petrópolis: Instituto Ecoar para a Cidadania, 2001. p. 99-138.

PAREDES, J.; ARRUDA, R. D. La motivación del uso de las tic em la formación de professorado em educación ambiental. Ciência \& Educação, v. 18, n. 2, p. 353-368, 2012. Acesso em: 12/12/2016.

RODRIGUES, G. S. de S. C.; COLESANTI, M. T. de M. Educação ambiental e as novas tecnologias de informação e comunicação. Sociedade \& Natureza, v. 20, n. 1, p. 51-66, 2008. Acesso em: 09/12/2016.

ROMÁN NUNEZ, Y. C.; CUESTA MORENO, O. J. Comunicación y conservación ambiental: avances y retos em Hispanoamérica. Revista Latina de Comunicación Social, v. 71, p. 15-39, 2016. Acesso em: 20/12/2016.

SAUVÈ, L. Uma cartografia das correntes em Educação Ambiental. In: SATO, M.; CARVALHO, I. C. M. (Org.). Educação Ambiental. Porto Alegre: Artmed, 2005. p. 17- 44.

SORRENTINO, M. Educação Ambiental e Universidade: um estudo de caso. Tese (Doutorado em Educação). Universidade de São Paulo, São Paulo, 1995. 
SORRENTINO, M. De Tbilissi a Thessalonik: a educação ambiental no Brasil. In: QUINTAS, J. S. (Org.) Pensando e praticando a educação ambiental no Brasil. Brasília: IBAMA, 2006. p. 107-118.

SULAIMAN, S. N. Educação ambiental, sustentabilidade e ciência: o papel da mídia na difusão de conhecimentos científicos. Ciência \& Educação, v. 17, n. 3, p. 645-662, 2011. Acesso em: 19/12/2016.

VIEIRA, F. Z.; ROSSO, A. J. O cinema como componente didático da educação ambiental. Revista Diálogo Educacional, v. 11, n. 33, p. 547-572, 2011. Acesso em: 19/12/2016. 